\title{
A Blueprint for Movement: Functional and Anatomical Representations in the Human Motor System
}

\author{
Michel Rijntjes, ${ }^{1}$ Christian Dettmers, ${ }^{1}$ Christian Büchel, ${ }^{2}$ Stefan Kiebel, ${ }^{1}$ Richard S. J. Frackowiak, ${ }^{2}$ and \\ Cornelius Weiller ${ }^{1}$
}

${ }^{1}$ Department of Neurology, Friedrich Schiller University, 07740 Jena, Germany, and 2Wellcome Department of Cognitive

Neurology, London WC1 NBG, United Kingdom

\begin{abstract}
Despite a clear somatotopic organization of the motor cortex, a movement can be learned with one extremity and performed with another. This suggests that there exists a limbindependent coding for movements. To dissociate brain regions coding for movement parameters from those relevant to the chosen effector, subjects wrote their signature with their dominant index finger and ipsilateral big toe, and we determined those areas activated by both conditions using functional magnetic resonance imaging. The results show that movement parameters for this highly trained movement are stored in sec-
\end{abstract}

Based on anatomical and functional criteria, the cortex of the human brain is divided in primary, secondary, and tertiary areas, with anatomical representation predominantly in primary cortex and modality-independent, functional representation in tertiary structures (Mesulam, 1987). The primary sensorimotor cortex shows a clear somatotopic representation of body parts (Penfield and Boldrey, 1938), albeit with some overlap (Förster, 1936; Schieber and Hibbard, 1993; Sanes et al., 1995). This area has the strongest anatomical connections with the limbs, and measuring cerebral activity with functional imaging tools like positron emission tomography or functional magnetic resonance imaging during a hand movement will show an activation of the primary hand region, irrespective of the task. Additional involvement of secondary and tertiary cortices will depend on the complexity of the paradigm, and activation in secondary motor cortices is generally interpreted as higher-order but still modality-specific processing, e.g., planning, preparation, imagining, selection, or internal generation of the movement (Passingham, 1993). It is implicitly assumed that this additional activation of secondary sensorimotor cortices is also limb-specific, since it is always seen as reflecting inherent aspects of the investigated movement, usually performed by the hand (Passingham 1989; Sakata and Taira, 1994; Jackson and Husain, 1996, Sanes and Donoghue, 1997; Rizzolatti et al., 1998). However, when making a movement, the parts of the brain involved in its execution depend on two determinants: on the extremity that is used and on the kind of movement that is being made. The observation that the same movement can be executed by different effectors has been called "motor equivalence" by Lashley (1930) and suggests that movement parameters are coded

Received Feb. 19, 1999; revised June 18, 1999; accepted June 30, 1999.

This work was supported in part by the Bundeministerium für Bildung und Forschung (Bonn, Germany). C.B. and R.S.J.F. are supported by the Wellcome Trust.

Correspondence should be addressed to Michel Rijntjes, Department of Neurology, Friedrich Schiller University, Philosophenweg 3, 07740 Jena, Germany.

Copyright (C) 1999 Society for Neuroscience $0270-6474 / 99 / 198043-06 \$ 05.00 / 0$ ondary sensorimotor cortices of the extremity with which it is usually performed, i.e., the dominant hand, including dorsal and ventral lateral premotor cortices. These areas can be accessed by the foot and are therefore functionally independent from the primary representation of the effector. Thus, somatotopy in secondary structures in the human motor system seems to be defined functionally, and not on the basis of anatomical representations.

Key words: human; motor system; movement; premotor cortex; visuospatial; representation; fMRI

independently from the limb representation itself. The demonstration that movement parameters are stored independently from the executing extremity and can be accessed by another may have implications for the rehabilitation of patients with circumscribed brain lesions, like stroke.

Signing one's name is a very characteristic hand movement. However, when standing on the beach, you can write your signature with your toe in the sand, retaining the personal characteristics (Rosenbaum, 1991; Rothwell, 1995). Apparently the foot, although it has never learned this movement, has immediate access to a motor program for the hand. By dissociating brain structures where parameters for a motor program are stored from those relevant to the chosen effector, it should be possible to separate anatomical and functional representations in the motor system. To this purpose, we chose signing as a movement that is exclusively associated with one extremity, i.e., the dominant hand, and had it perform with another.

Using functional magnetic resonance imaging, the first step was to determine the anatomical representations of finger and toe, as defined by a generic, zigzagging movement, which was performed either by the index finger or the big toe by nine healthy, righthanded subjects. To find areas containing the limb-independent, functional representation of signing, we had the same subjects sign with their right index finger and with the right big toe and identified the cerebral structures common to both.

\section{MATERIALS AND METHODS}

The subjects (eight male, one female, mean age, 32 years) were righthanded according to the Edinburgh Inventory (Oldfield, 1971). They signed approximately once every $4 \mathrm{sec}$ with their right dominant index finger or right big toe. For the zigzagging conditions, subjects were requested to perform a left-to-right zigzagging movement with the same finger and toe. Both the singing and the zigzagging conditions involved a small side-to-side movement of the hand and foot as well, but the lower arm and lower leg were supported comfortably to prevent innervation of proximal muscles. Signing is a more complex movement than zigzagging, but to minimize the differences between the movements, subjects exer- 
cised the zigzagging conditions before scanning to have the same frequency as signing, filling out the same space as their individual signatures, to ensure that the zigzagging conditions had similar spatial and directional properties as signing. The number of individual signatures and zigzagging movements were counted by an observer looking into the scanner and differed maximally by two movements at the end of the experiment. The space filled out by signing and zigzagging remained constant and was approximately the same. Eyes were closed during all conditions, including rest. Off-line electrooculographic and electromyographic recordings $(10 \mathrm{~Hz}-1 \mathrm{kHz}$ filter; $0.1 \mathrm{sec} /$ division; sensitivity, 100 $\mathrm{mV}$ ) during $2.5 \mathrm{~min}$ showed that there were no task-associated eye movements and no coinnervation of one extremity when moving another.

Neural activity was indexed by monitoring blood-oxygen leveldependent signal changes with functional magnetic resonance imaging. Data were acquired at the Wellcome Department of Cognitive Neurology in London with a $2 \mathrm{~T}$ magnetic resonance imaging (MRI) (Magnetom Vision, Siemens, Erlangen, Germany) whole-body scanner equipped with a head volume coil. Contiguous multislice $\mathrm{T} 2 *$-weighted images $[\mathrm{TE}=40 \mathrm{msec}, 90 \mathrm{msec} / \mathrm{image}, 64 \times 64$ pixels (voxel size, $3 \times 3 \times 3$ $\mathrm{mm})$ ] were obtained with echoplanar imaging using an axial slice orientation. The volume covered the whole brain $(14.4 \mathrm{~cm})$. The effective repetition time was $4.0 \mathrm{sec}$ per volume. In all conditions (four movement conditions and one rest condition), six image volumes were acquired, lasting $24 \mathrm{sec}$ each. Each movement condition was alternated with one rest condition. The four conditions containing a movement (six images each) were performed nine times in a random order. Alternated with rest scans (six images each), this resulted in 432 scans in total. At the end of each scan, the subject was instructed acoustically about the condition in the next one. Scans were realigned to each other and coregistered to an individual three-dimensional T1-weighted scan (voxel size, $1 \times 1 \times 1$ $\mathrm{mm})$. Image transformation into the stereotactic anatomical space was followed by smoothing with a $6 \mathrm{~mm}$ isotropic Gaussian kernel. Data analysis was performed by modeling the different conditions as reference waveforms (i.e., box-car functions convolved with a hemodynamic response function) in the context of the general linear model as employed by SPM96 (Frackowiak et al., 1997). Significant increases were tested with $t$ statistics, corrected for multiple comparisons, and displayed as a statistical parametric map, which was projected onto the averaged anatomical T1 image from the nine subjects. Threshold for significance was set at $p<0.001$. Two kinds of group comparisons were performed. The first was categorical, comparing zigzagging versus rest and signing versus rest. The second was conjunctional, identifying structures that were common to signing with either digit as compared to zigzagging, i.e., finger signing versus finger zigzagging and toe signing versus toe zigzagging (Price and Friston, 1996). For the conjunctional analysis, voxels with an interaction between conditions were rejected. The study was approved by the local ethics committee. Informed consent of all subjects was obtained before scanning.

\section{RESULTS}

\section{Anatomical representation as defined by simple, repetitive movements}

The zigzagging conditions, as compared with rest, activated most components of the sensorimotor system (Figs. 1, 2). Somatotopic segregation of hand and foot representations were found in the contralateral primary sensorimotor cortex, the adjacent superior parietal lobe (Brodmann area 5), supplementary motor area (SMA), the anterior cingulate, thalamus, basal ganglia (putamen, caudate nucleus, globus pallidus), cerebellar hemisphere, and vermis, following known primate anatomy and previous imaging studies (Nitschke et al., 1996; Fink et al., 1997; Lehericy et al., 1998). Our data also showed somatotopy for finger and toe in the dorsal lateral premotor cortex (PMd), in accordance with nonhuman primate studies (Kurata, 1989; He et al., 1993; Godschalk et al., 1995). The ventral activation of the precentral gyrus (Brodmann area 6) was located in the part of the ventral premotor cortex (PMv) that has been denoted F4 in monkeys (Matelli et al., 1985; Fink et al., 1997). Zigzagging with the finger gave rise to two foci of activation in the intraparietal sulcus. There is considerable individual variation in the course of this sulcus, but anal- ysis of the normalized T1-weighted anatomical images confirmed that the peaks of activations were in the intraparietal sulcus in each subject. The medial peak, commensurate with the activation in Brodmann area 5, probably corresponds to the middle intraparietal area (MIP), regarded as an intraparietal extension of area 5 (Caminiti et al., 1996). The lateral peak was at the fundus of the intraparietal sulcus, where the ventral intraparietal area (VIP) is located in monkeys (Colby et al., 1993). Zigzagging with the toe showed no activation in the intraparietal sulcus or in the premotor cortex of the hand at the level of the primary hand representation, even when the threshold was lowered to $p<0.05$. Zigzagging either with the finger or the toe activated the secondary sensorimotor system, consisting of the frontal operculum and secondary sensory cortex (SII).

\section{Functional representation as defined by a typical hand movement performed by finger and toe}

Signing with the finger, compared with rest, activated the same areas as zigzagging with the finger, with the addition of the posterior parietal cortex and the occipitotemporal junction (Figs. $1,2)$. Singing with the toe, compared with rest, activated the same areas as zigzagging with the toe, also with the addition of the posterior parietal cortex and the occipitotemporal junction. Signing with the toe activated the intraparietal sulcus and the premotor cortices on the convexity as well, i.e., secondary sensorimotor areas of the finger. The cerebral structures that were involved in signing independently of the executing extremity were defined by activations that were common to the comparisons finger signing versus finger zigzagging and toe signing versus toe zigzagging. This conjunctional analysis showed that signing with either limb was associated with an activation in areas that belonged to the anatomical finger representation in secondary cortices, as determined by the previous zigzagging conditions. These included the anterior part of the PMd, PMv, SMA, area MIP and VIP in the intraparietal sulcus, the thalamus, and the cerebellar hemispheres (Figs. 1, 2).

During signing, no significant voxels were found in the areas that were activated by zigzagging with the toe only. Activations additional to the zigzagging conditions were observed in the posterior part of the superior parietal cortex, probably corresponding to Brodmann area 7, and at the occipitotemporal junction, at the same location where the visual motion center (V5/ MT) has been described (Watson et al., 1993). All subjects reported a strong visual image of their signature while signing.

Statistical comparison of the signing and the zigzagging conditions revealed that there was no significant difference in activation of the respective primary sensorimotor cortices, as well as in area 5, basal ganglia, frontal operculum, and secondary sensory cortex. Therefore, these areas were not found in the conjunctional analysis of extremity-independent movement representations.

\section{DISCUSSION}

The execution of a typical hand movement, even when it is performed by the toe, involves "hand areas" at all levels of the anatomical hand representation, including secondary sensorimotor cortex, the thalamus, and the cerebellum, but excluding the primary sensorimotor cortex and basal ganglia. How can this be explained? Experimental results in humans show that movement trajectories are planned in an internal model of visually based kinematic coordinates (Soechting and Flanders, 1989; Wolpert et al., 1995). In nonhuman primates, a ventral and a dorsal parietofrontal network have been implicated in such visuomotor trans- 


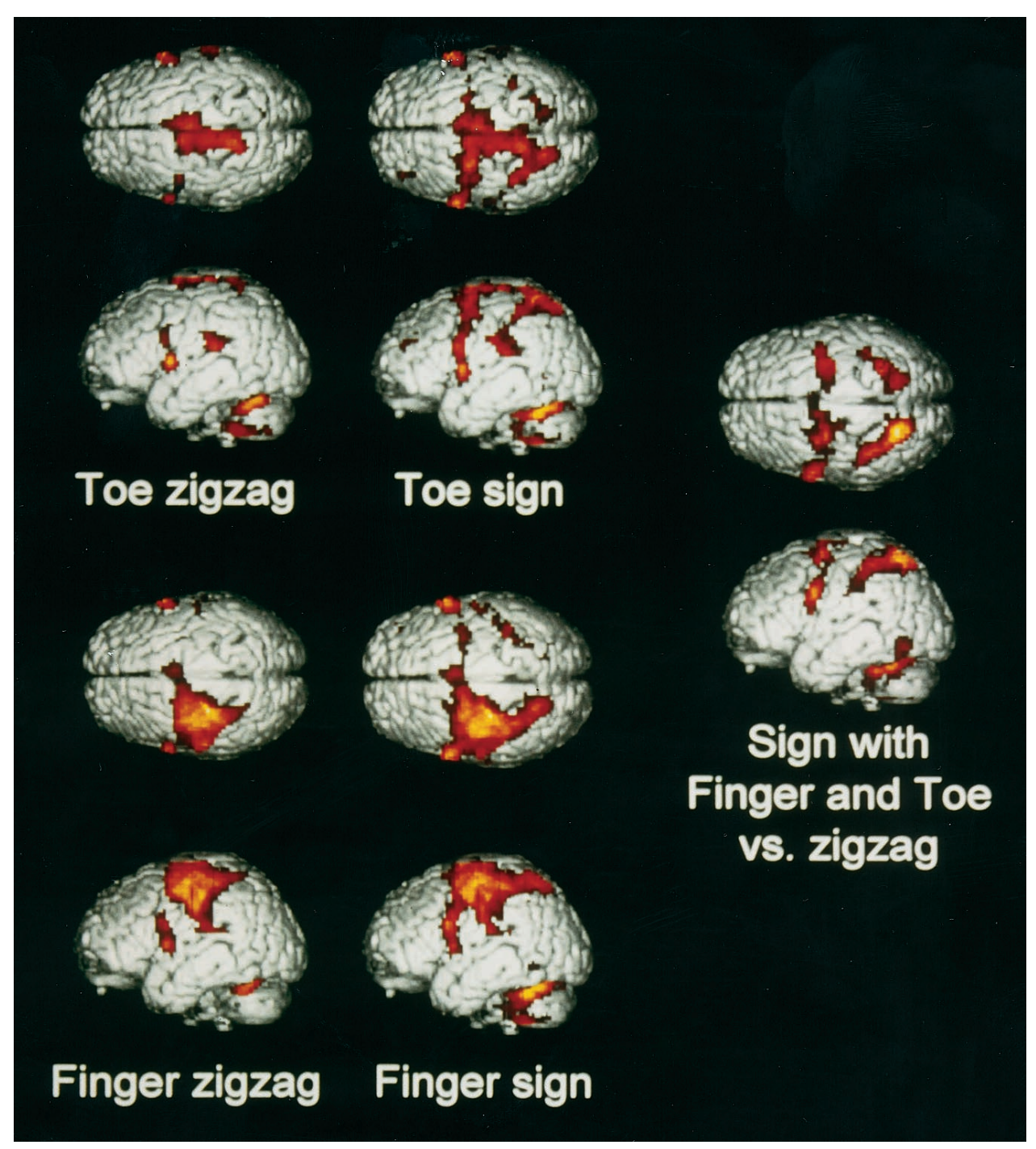

Figure 1. Anatomical and functional representations: surface views. Cortical activations of the different comparisons in the group of nine normal subjects. Activations in sulci as well as on gyri are projected on the surface of superior and lateral views of the brain. Top, Toe zigzagging versus rest (left) and toe signing versus rest (right). Bottom, Finger zigzagging versus rest (left) and finger signing versus rest (right). Right, Areas commonly activated in the conjunctional analysis of the two comparisons: finger signing versus finger zigzagging and toe signing versus toe zigzagging. In the zigzagging conditions, there is a clear somatotopic segregation for the toe in the midline and for the finger on the convexity, with some overlap in SMA and PMd (see Fig. 2, transverse slices). Zigzagging both with the toe and finger activated part of the PMv on the precentral gyrus, as well as the secondary sensorimotor system in the frontal operculum and secondary sensory cortex. Signing with the finger activated the same areas as zigzagging with the finger, with the addition of the posterior parietal cortex and the occipitotemporal junction. Signing with the toe activated the same areas as zigzagging with the toe, plus the posterior parietal cortex and the occipitotemporal junction, with the addition of the intraparietal sulcus and the premotor cortices on the convexity, i.e., the secondary sensorimotor areas of the finger. The conjunctional analysis of the signing conditions versus the respective zigzagging conditions revealed that the areas involved in signing, irrespective of the performing extremity, are the secondary sensorimotor areas that are part of the anatomical finger representation. These comprise PMv, PMd, and the intraparietal sulcus. Additionally, signing both with the finger and the toe activated the occipitotemporal junction and the posterior part of the superior parietal cortex. Signing activated the respective primary sensorimotor cortices of finger and toe, area 5, SII, and the frontal operculum to the same extent as zigzagging. Therefore, these areas are not involved in the extremity-independent representation of this automated movement.

formations of movement (Passingham, 1989; Kalaska et al., 1997; Rizzolatti et al., 1998), with PMv and PMd as the prerolandic components of these respective systems.

The ventral system, including VIP and PMv, has anatomical connections to the occipitotemporal junction (area V5/MT). This area, originally described as a visual motion center (Watson et al., 1993), has directional specificity (Tootell et al., 1995) and can be activated during illusory movement (Parsons et al., 1995). Apparently, because eyes were closed in all our tasks, V5/MT can be activated even without visual sensory input. V5/MT projects to VIP in the intraparietal sulcus (Colby et al., 1993), which is connected mainly with PMv (Matelli et al., 1994). In both these areas, many neurons are bimodal, in the sense that they respond to stimuli in both tactile and visual fields. These visual receptive fields extend from the tactile receptive fields into adjacent space and move as a unit with it (Fogassi et al., 1996; Graziano et al., 1997). This system, coding for target localization in peripersonal space in body part-centered coordinates, was activated contralateral to the signing hand or foot.

The dorsal system includes MIP and PMd and is located in secondary sensory areas embracing the primary hand representation (Wise et al., 1997; Rizzolatti et al., 1998). Neuronal activity 


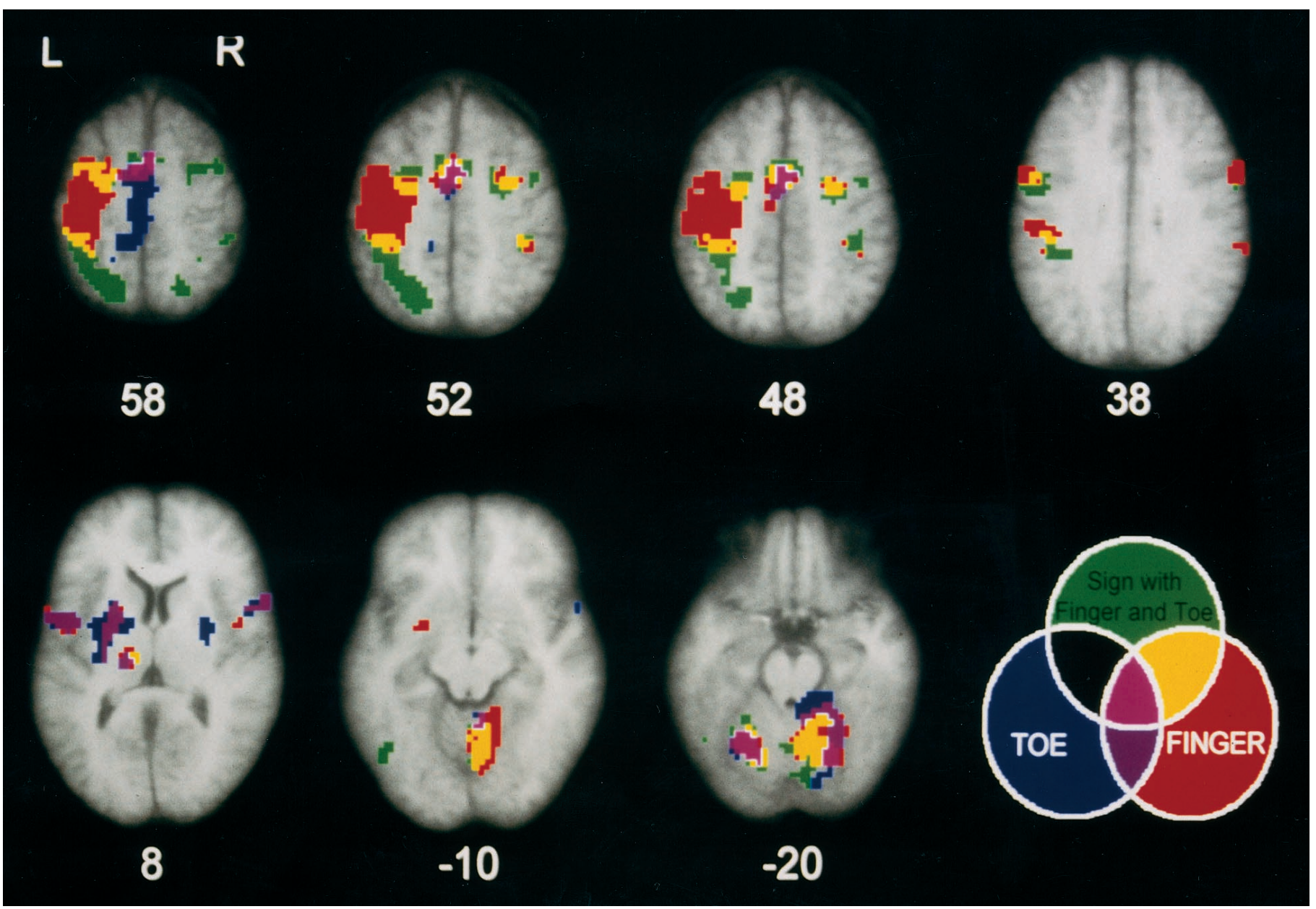

Figure 2. Anatomical and functional representations: axial slices. Transverse slices with activations superimposed on the averaged T1 images of the nine subjects. Neurological convention (left $=$ left), numbers refer to millimeters relative to the intercommissural line. Displayed are activations at the level of PMd of the hand (48-58 mm), SMA (52 mm), VIP and PMv (38 mm), thalamus and putamen $(8 \mathrm{~mm})$, cerebellar vermis $(-10 \mathrm{~mm})$, and the cerebellar hemisphere $(-20 \mathrm{~mm})$. The slice at $38 \mathrm{~mm}$ was pitched down by $6^{\circ}$ to capture both VIP and PMv. The three circles in the diagram represent three comparisons: zigzagging with the finger versus rest, zigzagging with the toe versus rest, and the conjunctional analysis of areas common to signing with finger and toe versus zigzagging with either. The areas where these comparisons overlap or not are coded in separate colors. Red, Areas activated by finger zigzagging only, excluding the overlap with the conjunctional analysis of signing with the finger and the toe. Blue, Areas activated by toe zigzagging only, excluding the conjunctional analysis of signing with the finger and the toe. Dark purple, Overlap of activations by zigzagging with the finger and the toe, excluding the conjunctional analysis of signing with the finger and the toe. Green, Areas involved in the conjunctional analysis of signing with the finger and the toe, additional to the zigzagging conditions. The ipsilateral and contralateral activations for signing were slightly larger than for zigzagging in several areas, because signing is a more complex movement than zigzagging (see Discussion). Light purple, Areas activated by zigzagging with the finger and the toe, which are also involved in signing with either. Black, There were no areas found that are activated by zigzagging with the toe and that are also involved in the conjunctional analysis of signing with the finger and the toe. Yellow, Areas that were found in the conjunctional analysis of signing with finger and toe versus zigzagging with either and were also found in zigzagging with the finger only, excluding areas activated by finger and toe zigzagging. These areas comprised secondary cortices, thalamus, and cerebellum as part of the anatomical finger representation, excluding the primary sensorimotor cortex, area 5, basal ganglia, frontal operculum, and secondary sensory cortex. Signing did not activate exclusive toe areas. Thus, the limb-independent motor representation of signing is confined to finger areas, excluding exclusive toe areas, with additional activation of the posterior parietal lobe and occipitotemporal junction.

in these interconnected areas correlates with both external and limb coordinate spaces, subserving visuomotor transformations by reference to an external, visuospatial reference frame (Boussaoud 1995; Johnson et al., 1996; Shen and Alexander, 1997). Activation of this system in the present study was bilateral, a finding consistent with studies on explicit (Stephan et al., 1995) and implicit (Parsons et al., 1995) motor imagery of the dominant hand.

In this dorsal system, area PMd has been suggested as the most probable place where movement parameters from an allocentric, visuospatial reference frame are transformed into limb-centered movement descriptions (Kalaska and Crammond, 1992; Kalaska et al., 1997; Wise et al., 1997). In our study, the analysis of limb-independent representations of movements revealed involvement of the anterior part of the PMd only. A functional subdivision within the PMd of humans (Deiber et al., 1991; Grafton et al., 1998) and nonhuman primates (Johnson et al., 1996) has been suggested before, with activity in the anterior part associated with target localization and selection or preparation for movement and the posterior part with its execution. The basis for this functional division is found in anatomical studies in primates, where area 5 is interconnected predominantly with the primary motor cortex and posterior PMd, whereas area MIP projects mainly to anterior PMd (Strick and Kim, 1978; Ghosh and Gattera, 1995; Tanne et al., 1995). This latter area has no 
direct projections to M1, and indirectly only through posterior PMd (Barbas and Pandya, 1987). Our study shows that movement parameters are coded in the system that includes anterior PMd and MIP, which, like the ventral system, is part of the anatomical hand representation, but functionally independent. In these areas, a movement is coded for by a set of extrinsic kinematic attributes. The posterior PMd, primary sensorimotor cortex, and adjacent area 5 are hierarchically further "downstream", where movement parameters code for the intrinsic kinematics of the executing extremity. This explains why these areas, coding for the limb-specific instructions, were not found in the analysis of limbindependent movement representation.

The posterior part of the superior parietal cortex (Brodmann area 7), which was activated by signing additionally to the zigzagging conditions, has been shown to play a role in the visual guidance of movements, especially when retrieved from memory (Kawashima et al., 1995), and lesions to this area cause disturbance of such functions (Pause et al., 1989; Karnath, 1997). It is thought to code for a multimodal, abstract representation of space (Andersen et al., 1997).

Our data suggest that the functional representation of a highly trained movement of the dominant hand is coded in neural assemblies that are part of the anatomical representation of the limb with which it is usually performed. Both the egocentric coordinate system (based on PMv) and the allocentric reference frame (based on PMd) of the dominant hand are engaged by the movement of signing, even when it is performed by the toe. Movement parameters for an overlearned movement are therefore stored independently from the executing extremity. The determinant for somatotopy in sensorimotor structures other than primary cortex and basal ganglia is not the limb with which a movement is actually performed, but the limb with which it is habitually associated. These areas constitute the intersection of anatomical and functional representation in the human brain.

\section{REFERENCES}

Andersen RA, Snyder LH, Bradley DC, Xing J (1997) Multimodal representation of space in the posterior parietal cortex and its use in planning movements. Annu Rev Neurosci 20:303-330.

Barbas H, Pandya DN (1987) Architecture and frontal cortical connections of the premotor cortex (area 6) in the rhesus monkey. J Comp Neurol 256:211-228.

Boussaoud D (1995) Primate premotor cortex: modulation of preparatory neuronal activity by gaze angle. J Neurophysiol 73:886-890.

Caminiti R, Ferraina S, Johnson PB (1996) The sources of visual information to the primate frontal lobe: a novel role for the superior parietal lobe. Cereb Cortex 6:319-328.

Colby CL, Duhamel JR, Goldberg ME (1993) Ventral intraparietal area of the macaque: anatomic location and visual response properties. J Neurophysiol 69:902-914.

Deiber MP, Passingham RE, Colbatch JG, Friston KJ, Nixon PD, Frackowiak RSJ (1991) Cortical areas and the selection of movement: a study with positron emission tomography. Exp Brain Res 84:393-402.

Fink GR, Frackowiak RSJ, Pietrzyk U, Passingham R (1997) Multiple non-primary motor areas in the human cortex. J Neurophysiol 67:1264-2174.

Fogassi L, Gallese L, Fadiga L, Luppino G, Matelli M, Rizzolatti G (1996) Coding of peripersonal space in inferior premotor cortex (area F4). J Neurophysiol 76:141-157.

Förster O (1936) The motor system in man in the light of Hughlings Jackson's doctrines. Brain 59:135-159.

Frackowiak RSJ, Friston K, Frith CD (1997) Human brain function. San Diego, CA: Academic.

Ghosh S, Gattera R (1995) A comparison of the ipsilateral cortical projections to the dorsal and ventral subdivisions of the macaque premotor cortex. Somatosens Mot Res 12:359-378.

Godschalk M, Mitz AR, van Duin B, van den Burg H (1995) Somatotopy of monkey premotor cortex examined with microstimulation. Neurosci Res 23:269-279.

Grafton ST, Fagg AH, Arbib MA (1998) Dorsal premotor cortex and conditional movement selection: a PET functional mapping study. J Neurophysiol 79:1092-1097.

Graziano MS, Hu XT, Gross CG (1997) Visuospatial properties of ventral premotor cortex. J Neurophysiol 77:2268-2292.

He S, Dum R, Strick P (1993) Topographic organization of corticospinal projections from the frontal lobe: motor areas on the lateral surface of the hemisphere. J Neurosci 13:952-980.

Jackson S, Husain M (1996) Visuomotor functions of the lateral premotor cortex. Curr Opin Neurobiol 6:788-795.

Johnson PB, Ferraina S, Bianchi L, Caminiti R (1996) Cortical networks for visual reaching: physiological and anatomical organization of frontal and parietal lobe arm regions. Cereb Cortex 6:102-119.

Kalaska JF, Crammond DJ (1992) Cerebral cortical mechanisms of reaching movements. Science 255:1517-1523.

Kalaska JF, Scott SH, Cisek P, Sergio LE (1997) Cortical control of reaching movements. Curr Opin Neurobiol 7:849-859.

Karnath HO (1997) Spatial orientation and the representation of space with parietal lobe lesions. Philos Trans R Soc Lond B Biol Sci 352:1411-1419.

Kawashima R, Roland PE, O’Sullivan BT (1995) Functional anatomy of reaching and visuomotor learning: a positron emission tomography study. Cereb Cortex 5:111-122.

Kurata K (1989) Distribution of neurons with set- and movement-related activity before hand and foot movements in the premotor cortex of rhesus monkeys. Exp Brain Res 77:245-256.

Lashley K (1930) Basic neural mechanisms in behavior. Psychol Rev $37: 1-24$.

Lehericy S, van de Moortele PF, Lobel E, Paradis AL, Vidailhet M, Frouin V, Neveu P, Agid Y, Marsault C, Le Bihan D (1998) Somatotopical organization of striatal activation during finger and toe movement: a 3-T functional magnetic resonance imaging study. Ann Neurol 44:398-404.

Matelli M, Luppino G, Rizzolatti G (1985) Pattern of cytochrome oxidase activity in frontal agranular cortex of the macaque monkey. Behav Brain Res 18:125-136.

Matelli M, Luppino A, Murata A, Sakata H (1994) Independent anatomical circuits for reaching and grasping linking inferior parietal lobule and inferior area 6 in the monkey. Soc Neurosci Abstr 20:404.

Mesulam M-M (1987) Patterns in behavioral neuroanatomy: association areas, the limbic system, and hemispheric specialization. In: Principles of behavioral neurology (Mesulam M-M, ed) pp 1-70. Philadelphia: F.A. Davis.

Nitschke MF, Keinschmidt A, Wessel K, Frahm J (1996) Somatotopic motor representation in the human anterior cerebellum. A highresolution functional MRI study. Brain 119:1023-1029.

Oldfield R (1971) The assessment and analysis of handedness: the Edinburgh inventory. Neuropsychologia 9:97-113.

Parsons LM, Fox PT, Downs JH, Glass T, Hirsch TB, Martin CC, Jerabek PA, Lancaster JL (1995) Use of implicit motor imagery for visual shape discrimination as revealed by PET. Nature 375:54-58.

Passingham RE (1989) Premotor cortex and the retrieval of movement. Brain Behav Evol 33:189-192.

Passingham RE (1993) The frontal lobes and voluntary action. Oxford: Oxford UP.

Pause M, Kunesch E, Binkofski F, Freund HJ (1989) Sensorimotor disturbances in patients with lesions of the parietal cortex. Brain 112:1599-1625.

Penfield W, Boldrey E (1938) Somatic motor and sensory representation in the cerebral cortex of man as studied by electrical stimulation. Brain 15:389-443.

Price CJ, Friston KJ (1996) Cognitive conjunction: a new approach to brain activation experiments. NeuroImage 5:261-270.

Rizzolatti G, Luppino G, Matelli M (1998) The organization of the cortical motor system: new concepts. Electroencephalogr Clin Neurophysiol 106:283-296.

Rosenbaum DA (1991) Human motor control. San Diego, CA: Academic.

Rothwell J (1995) Control of human voluntary movement. London: Chapman \& Hall. 
Sakata H, Taira M (1994) Parietal control of hand action. Curr Opin Neurobiol 4:847-856.

Sanes J, Donoghue J (1997) Static and dynamic organization of motor cortex. In: Brain plasticity (Freund HJ, ed) pp 277-296. Philadelphia: Lippincott-Raven.

Sanes J, Donoghue J, Thangaraj V, Edelman R, Warach S (1995) Shared neural substrates controlling hand movements in human motor cortex. Science 268:1775-1777.

Schieber M, Hibbard L (1993) How somatotopic is the motor cortex hand area? Science 261:489-492.

Shen L, Alexander GE (1997) Preferential representation of instructed target location versus limb trajectory on dorsal premotor cortex. J Neurophysiol 77:1195-1212.

Soechting JF, Flanders M (1989) Sensorimotor representations for pointing to targets in three-dimensional space. J Neurophysiol 62:582-594.

Stephan KM, Fink GR, Passingham RE, Silbersweig D, CeballosBaumann AO, Frith CD, Frackowiak RSJ (1995) Functional anatomy of the mental representation of upper extremity movements in healthy subjects. J Neurophysiol 73:373-386.

Strick PL, Kim CC (1978) Input to primate motor cortex from posterior parietal cortex (area 5). 1. Demonstration by retrograde transport. Brain Res 157:325-330.

Tanne J, Boussaoud D, Boyer-Zeller N, Rouiller E (1995) Parietal inputs to physiologically defined regions of dorsal premotor cortex in the macaque monkey. Eur J Neurosci 8:195-201.

Tootell RBH, Reppas JB, Dale AM, Look RB, Sereno MI, Malach R, Brady TJ, Rosen BR (1995) Visual motion aftereffect in human cortical area MT revealed by functional magnetic resonance imaging. Nature 375:139-141.

Watson JDG, Myers R, Frackowiak RSJ, Hajnal JV, Woods RP, Mazziotta JC, Shipp S, Zeki S (1993) Area V5 of the human brain: evidence from a combined study using positron emission tomography and magnetic resonance imaging. Cereb Cortex 3:79-94.

Wise SP, Boussaoud D, Johnson PB, Caminiti R (1997) Premotor and parietal cortex: corticocortical connectivity and combinatorial computations. Annu Rev Neurosci 20:25-42.

Wolpert DM, Ghahramani, Z, Jordan, MI (1995) Are arm trajectories planned in kinematic or dynamic coordinates? An adaptation study. Exp Brain Res 103:460-470. 